\title{
Interstitial insulin kinetic parameters for a 2-compartment insulin model with saturable clearance
}

\author{
Christopher Pretty,* Aaron Le Compte,* Geoffrey Shaw,** J. Geoffrey Chase* \\ * University of Canterbury, Centre for Bioengineering, Christchurch, New Zealand \\ (Tel: +64 3364 2596; e-mail: Christopher.Pretty@pg.canterbury.ac.nz). \\ **University of Otago, Dept of Intensive Care, Christchurch, New Zealand
}

\begin{abstract}
Glucose-insulin system models are commonly used for identifying insulin sensitivity, either for glycaemic control or diagnostic purposes. With physiological, 2-compartment insulin kinetics models, accurate kinetic parameter values are necessary to obtain reliable estimates of insulin sensitivity. This study combined data from 6 separate, published microdialysis studies to determine the best parameter values for the transcapillary diffusion rate $\left(n_{I}\right)$ and cellular insulin clearance rate $\left(n_{C}\right)$.

The 6 studies (12 data sets) used microdialysis techniques to assay interstitial insulin concentrations simultaneously with plasma insulin concentration samples. The reported arterial insulin concentrations were used as input and interstitial insulin concentrations were simulated with the interstitial insulin kinetics sub-model. These simulated results were then compared to the reported interstitial measurements and an error value calculated as the absolute difference at the original measurement time points, normalised by the mean interstitial insulin concentration. The most appropriate set of parameter values was determined across the 12 data sets by combining the results.

The results of this investigation suggest that the most appropriate values for the interstitial insulin kinetic parameters are $n_{I}=n_{C}=0.0060 \mathrm{~min}^{-1}$. These parameter values are associated with an effective, interstitial insulin half-life $t_{1 / 2}=58$ mins, within the range of $25-130$ mins reported by others.
\end{abstract}

Keywords: Biomedical system modeling, simulation and visualization; Control of physiological and clinical variables;

\section{INTRODUCTION}

Glucose-insulin system models are commonly used for identifying insulin sensitivity, either for glycaemic control or diagnostic purposes. Insulin-mediated glucose uptake primarily occurs from the interstitial fluid. Insulin from plasma diffuses to the interstitial fluid surrounding tissue cells where it binds to cell-wall receptors, activating glucose uptake (Jefferson and Cherrington, 2001). Modelling this behaviour with two insulin compartments is relatively common (Hovorka et al., 2008, Lin et al., 2011, Pielmeier et al., 2010, Van Herpe et al., 2006). However, directly measuring the kinetic parameter values is difficult, if not impossible, especially as many of these models treat the remote compartment as an effect compartment with no backdiffusion, rather than a physiological representation of a fluid space.

This study determines the kinetic parameter values for a twocompartment physiological model with saturable clearance, using data from a number of published microdialysis studies. The specific model used is that described by Lin et al. (2011). Although this model is very similar to those described by Lotz et al. (2008) and Pielmeier et al. (2010), the published insulin kinetic parameter values are quite different. Hence there is a need for clarification based physiological measurements.

\section{SUBJECTS AND METHODS}

This study used data from 6 published studies (see Table 1) that used microdialysis to assay interstitial insulin levels simultaneously with plasma insulin levels. These measurements enabled direct determination of the kinetic parameter values.

\subsection{Interstitial insulin kinetics model}

The interstitial insulin kinetics model used in this study was described by Lin et al. (2011) and is shown in (1). Plasma and interstitial insulin concentrations are denoted $I$ and $Q$, respectively. Receptor-bound insulin saturation dynamics are characterised by $\alpha_{\mathrm{G}}$.

There are only two parameters that affect interstitial insulin kinetics at physiological concentrations. The parameter $n_{I}$ represents the transcapillary diffusion rate between the $I$ and $Q$ compartments. The parameter $n_{C}$ represents the irreversible cellular insulin clearance rate. Thus, only one equation is required, and the desired variables are separated from any other equations, data, or parameter values, eliminating any other potential biases 


$$
\dot{Q}=n_{I}(I-Q)-\frac{n_{C} Q}{1+\alpha_{G} Q}
$$

The transformation shown in (2) defines $\gamma$, the steady state ratio of interstitial insulin (Q) to plasma insulin (I) concentrations, at physiological levels. In this study, the parameters $n_{I}$ and $\gamma$ are identified, from which $n_{C}$ can be calculated. The parameter $\gamma$ provides a more intuitive insight to the relative interstitial insulin concentration than $n_{C}$.

$$
\gamma=\frac{n_{I}}{n_{I}+n_{C}}
$$

\subsection{Microdialysis analysis}

To identify $n_{I}$ and $\gamma$ in a direct, physiological manner, data was used from 6 published studies (12 data sets). These studies used microdialysis to determine interstitial insulin concentrations. Plasma insulin concentrations were taken simultaneously. The 6 independent studies were conducted using infused and endogenous insulin at varying physiological and supra-physiological levels. Data used in this analysis was taken from the studies listed in Table 1.

Using reported arterial insulin concentrations $(I)$ as input, interstitial concentrations $(Q)$ were simulated with the interstitial insulin kinetics sub-model described in (1). These simulated results were then compared to the reported interstitial measurements.

A grid-search was performed over a range of $n_{I}$ and $\gamma$ values to find the region of minimum error between simulated and measured interstitial insulin concentrations. For any given parameter pair, the error value was defined as the sum of absolute differences between the simulated and measured concentrations at the experimental sampling points, divided by the average interstitial insulin level during the experiment. Errors across all data sets were evaluated by two methods to ensure robust parameter values that were not skewed by data from a single study. Specifically:

I. Each error value was weighted equally, by summing absolute error values at each $\left(n_{I}, \gamma\right)$ pair across all 12 data sets.

II. Each study was weighted equally by scaling the calculated errors into the range $0-1$ prior to summing across all data sets.

\begin{tabular}{|c|c|c|c|c|}
\hline Study & Study Method & Study Population & $\mathbf{N}$ & $\begin{array}{c}\text { Interstitial sampling } \\
\text { location }\end{array}$ \\
\hline Jansson et al. (1993) & $\begin{array}{l}\text { Euglycaemic- } \\
\text { hyperinsulinaemic clamp }\end{array}$ & Healthy non-obese & 5 & $\begin{array}{l}\text { Abdominal } \\
\text { subcutaneous fat }\end{array}$ \\
\hline \multirow{4}{*}{ Castillo et al. (1994) } & $\begin{array}{l}\text { Euglycaemic- } \\
\text { hyperinsulinaemic clamp }\end{array}$ & $\begin{array}{l}\text { Healthy: } \\
\text { Body fat }<=12 \%\end{array}$ & 3 & $\begin{array}{l}\text { Subcutaneous lymph } \\
\text { vessel; lower leg }\end{array}$ \\
\hline & $\begin{array}{l}\text { Euglycaemic- } \\
\text { hyperinsulinaemic clamp }\end{array}$ & $\begin{array}{l}\text { Healthy: } \\
\text { Body fat } 13-21 \%\end{array}$ & 5 & $\begin{array}{l}\text { Subcutaneous lymph } \\
\text { vessel; lower leg }\end{array}$ \\
\hline & $\begin{array}{l}\text { Euglycaemic- } \\
\text { hyperinsulinaemic clamp }\end{array}$ & $\begin{array}{l}\text { Healthy: } \\
\text { Body fat } 22-35 \%\end{array}$ & 3 & $\begin{array}{l}\text { Subcutaneous lymph } \\
\text { vessel; lower leg }\end{array}$ \\
\hline & $\begin{array}{l}\text { Euglycaemic- } \\
\text { hyperinsulinaemic clamp }\end{array}$ & $\begin{array}{l}\text { Healthy: } \\
\text { Body fat }>=36 \%\end{array}$ & 2 & $\begin{array}{l}\text { Subcutaneous lymph } \\
\text { vessel; lower leg }\end{array}$ \\
\hline \multirow{2}{*}{$\begin{array}{l}\text { Sjostrand et al. } \\
(2002)\end{array}$} & $\begin{array}{l}\text { Euglycaemic- } \\
\text { hyperinsulinaemic clamp }\end{array}$ & Healthy lean & 10 & Forearm muscle \\
\hline & $\begin{array}{l}\text { Euglycaemic- } \\
\text { hyperinsulinaemic clamp }\end{array}$ & Healthy obese & 10 & Forearm muscle \\
\hline $\begin{array}{l}\text { Gudbjornsdottir et al. } \\
(2003)\end{array}$ & $\begin{array}{l}\text { Euglycaemic- } \\
\text { hyperinsulinaemic clamp }\end{array}$ & Healthy lean & 10 & Forearm muscle \\
\hline \multirow{2}{*}{ Herkner et al. (2003) } & Oral glucose tolerance test & Healthy lean & 8 & Mid thigh muscle \\
\hline & $\begin{array}{l}\text { Euglycaemic- } \\
\text { hyperinsulinaemic clamp }\end{array}$ & Healthy lean & 8 & Mid thigh muscle \\
\hline \multirow{2}{*}{$\begin{array}{l}\text { Sjostrand et al. } \\
(2005 a)\end{array}$} & Oral glucose tolerance test & Healthy lean & 10 & Forearm muscle \\
\hline & Oral glucose tolerance test & Healthy obese & 10 & Forearm muscle \\
\hline
\end{tabular}

Table 1. Published microdialysis studies used to investigate interstitial insulin kinetic parameters. 


\section{RESULTS \& DISCUSSION}

Grid-search results for the parameter optimisation using published microdialysis data are shown in Figure 1. The left panel shows the results from method I where each error value was weighted equally. The right panel shows the results from method II where each study was weighted equally. Data from the Herkner et al. (2003) clamp study have been omitted as the minimum error was located at $n_{I}=0$, which was not physiologically reasonable.

Figure 1 shows the regions around the minimum error points, where the contours indicate errors $1 \%$ and $5 \%$ greater than the minimum values. The parameter set, $n_{I}=0.0060 \mathrm{~min}^{-1}, \gamma$ $=0.5\left(n_{I}=n_{C}\right)$ is enclosed within the $5 \%$ region and thus provides a good compromise between the two identified minima and previous results. The choice of $\gamma=0.5$ is consistent with that used by Lin et al. \{, $2011 \# 2257\}$ and similar to the value of 0.6 used by Lotz et al. \{, $2008 \# 1707\}$ and Pielmeier et al. \{, $2010 \# 3278\}$.

Table 2 shows the individual optimal parameter values for each dataset. The associated errors are shown along with the error obtained using the selected parameter set, $n_{I}$ $=0.0060 \mathrm{~min}^{-1}, \gamma=0.5$. The errors presented are unitless and represent the mean absolute error across the experimental sampling points for that study, normalised by the average interstitial insulin concentration during the experiment.

The optimal parameter values vary widely across the 12 data sets, particularly for $n_{I}$. This variability could reflect the inter-patient differences, poor mixing of interstitial fluid, the difficulty of microdialysis techniques or lack of sensitivity to these parameter values.
Figure 2 shows two contrasting examples of the simulated and measured interstitial insulin concentrations using the selected parameter values. Panels A and B show data from the Castillo study (1994) for subjects with body fat in the range of $13-21 \%$. Panels $C$ and D show data from the oral glucose tolerance test (OGTT) study by Herkner et al. (2003). Measured arterial insulin is presented in the top panels (A and $C$ ), with measured and modelled interstitial insulin in the bottom (B and D) along with the absolute error between them. These two studies had similar insulin concentrations and thus make a good comparison.

The model fit to data is very good for the Castillo study (1994) in the left panel, but less so for the Herkner study (2003) in the right panel. The interstitial insulin peak at 15 mins in the Herkner study does not correspond to any feature in the plasma insulin profile. The plasma insulin-sampling scheme may have missed a peak, the interstitial insulin peak may be spurious, or insulin may have been transported to the interstitium independent of plasma as the authors' propose.

The Herkner study was conducted using oral glucose (75 grams) to stimulate insulin secretion. Therefore, a sharp plasma insulin peak would not be expected (Caumo and Luzi, 2004), particularly within 15 minutes of glucose ingestion. The insulin kinetics model used for this analysis relies on passive diffusion of insulin across the endothelium. Hence, with no plasma insulin peak to create a sharp concentration gradient, the model could not reproduce the reported peak in interstitial insulin, resulting in the poor fit.
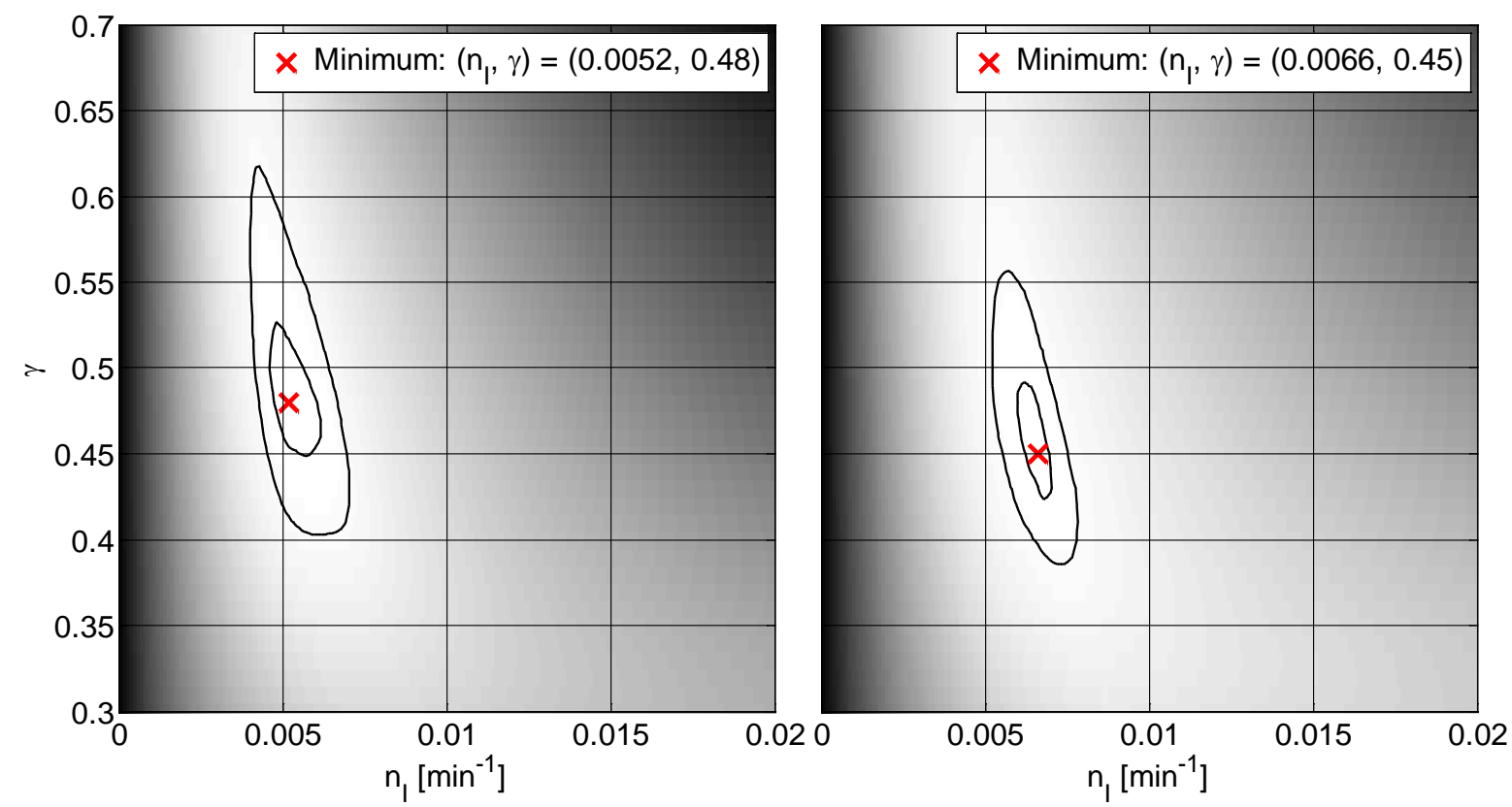

Figure 1. Grid-search error results from microdialysis analysis showing optimal parameter values. The left panel shows the results where each error value was weighted equally (method I), and the right panel shows the results where each study was weighted equally (method II). Contours are at error 1\% and 5\% greater than the minimum. Lighter areas represent lower error and darker areas, greater. 
Table 2. Individual results from published microdialysis studies. Study minimum error is associated with the study optimal $n_{I}$ and $\gamma$. The error at the selected parameter set, $n_{I}=0.0060 \mathrm{~min}^{-1}, \gamma=0.5$ is also shown. The errors are unitless and represent mean absolute error across the measurement points, normalised by the average interstitial insulin concentration. Abbreviations; Clamp: Euglycaemic-hyperinsulinaemic clamp; OGTT: Oral glucose tolerance test.

\begin{tabular}{|c|c|c|c|c|c|c|}
\hline Study & $\begin{array}{c}\text { Study } \\
\text { Method }\end{array}$ & Study Population & $\begin{array}{c}\text { Study } \\
\text { optimal } n_{I}\end{array}$ & $\begin{array}{c}\text { Study } \\
\text { optimal } \gamma\end{array}$ & $\begin{array}{c}\text { Study min. } \\
\text { error }\end{array}$ & $\begin{array}{c}\text { Error at } \\
\text { selected }\left(n_{l}, \gamma\right)\end{array}$ \\
\hline $\begin{array}{l}\text { Jansson et al. } \\
\text { (1993) }\end{array}$ & Clamp & Healthy non-obese & 0.0054 & 0.30 & 0.142 & 0.233 \\
\hline \multirow{4}{*}{$\begin{array}{l}\text { Castillo et al. } \\
(1994)\end{array}$} & Clamp & $\begin{array}{l}\text { Healthy: } \\
\text { Body fat }<=12 \%\end{array}$ & 0.0031 & 0.53 & 0.103 & 0.305 \\
\hline & Clamp & $\begin{array}{l}\text { Healthy: } \\
\text { Body fat } 13-21 \%\end{array}$ & 0.0048 & 0.62 & 0.038 & 0.090 \\
\hline & Clamp & $\begin{array}{l}\text { Healthy: } \\
\text { Body fat } 22-35 \%\end{array}$ & 0.0041 & 0.61 & 0.029 & 0.101 \\
\hline & Clamp & $\begin{array}{l}\text { Healthy: } \\
\text { Body fat >=36\% }\end{array}$ & 0.0040 & 0.44 & 0.044 & 0.204 \\
\hline \multirow{2}{*}{$\begin{array}{l}\text { Sjostrand et al. } \\
\text { (2002) }\end{array}$} & Clamp & Healthy lean & 0.0128 & 0.48 & 0.060 & 0.191 \\
\hline & Clamp & Healthy obese & 0.0054 & 0.70 & 0.057 & 0.072 \\
\hline $\begin{array}{l}\text { Gudbjornsdottir et } \\
\text { al. (2003) }\end{array}$ & Clamp & Healthy lean & 0.0061 & 0.67 & 0.143 & 0.180 \\
\hline \multirow{2}{*}{$\begin{array}{l}\text { Herkner et al. } \\
(2003)\end{array}$} & OGTT & Healthy lean & 0.0116 & 0.31 & 0.300 & 0.458 \\
\hline & Clamp & Healthy lean & 0 & 0 & 0.137 & 1.546 \\
\hline \multirow{2}{*}{$\begin{array}{l}\text { Sjostrand et al. } \\
\text { (2005a) }\end{array}$} & OGTT & Healthy lean & 0.0600 & 0.57 & 0.101 & 0.610 \\
\hline & OGTT & Healthy obese & 0.0400 & 0.46 & 0.058 & 0.516 \\
\hline
\end{tabular}
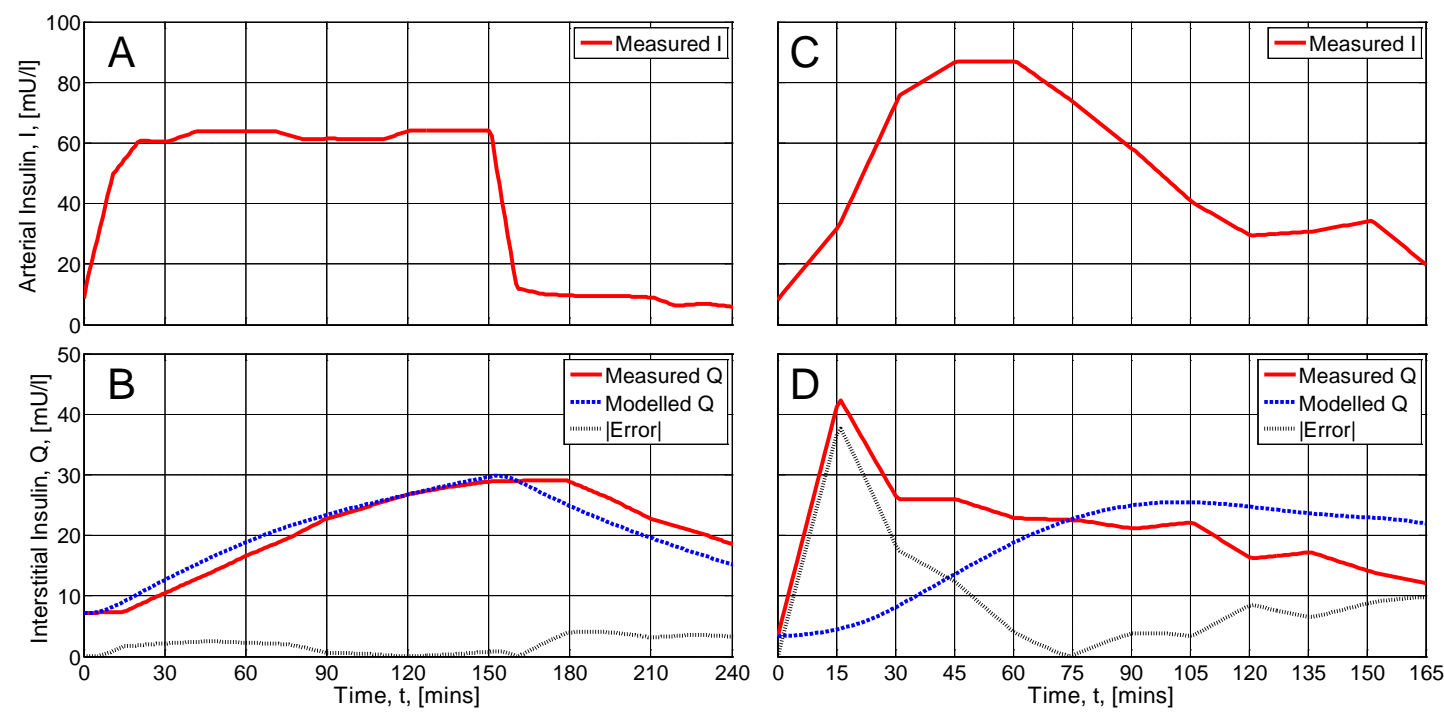

Figure 2. Two contrasting examples from the simulation of microdialysis data using selected parameter set, $n_{I}=0.0060$ min ${ }^{-1}$, $\gamma=0.5$. The panels on the left show a good model fit to measured data from Castillo et al. (1994) (body fat 13-21\%). The panels on the right show a poor fit from Herkner et al. (2003) (OGTT). The upper panels present plasma insulin concentrations and the lower panels measured and modelled interstitial insulin concentrations. 
Modelled interstitial insulin profiles did not fit either data set from the Herkner et al. (2003) study very well. The OGTT example from this study is shown in the right panel of Figure 2. The other data set from Herkner involved a euglycaemichyperinsulinaemic clamp procedure, in which the interstitial insulin levels were lower than during the OGTT study $(<10$ $\mathrm{mU} / \mathrm{l})$, despite sustained higher plasma levels $(>65 \mathrm{mU} / \mathrm{l}$ for 60 mins).

There were no obvious reasons for these poor fits and they may be due to the complicated and difficult nature of microdialysis sampling of interstitial fluid. As noted previously, data from the Herkner et al. (2003) clamp study were omitted.

The remaining studies had mean absolute error values at their individual optimal parameter values of less than $15 \%$ of their average interstitial insulin concentration. At the selected parameter set, the errors were less than 30\%, except for the OGTT study by Sjostrand et al. (2005a). The optimal $n_{I}$ values for these two datasets were very high $\left(n_{I}=0.060\right.$ and $0.040 \mathrm{~min}^{-1}$, respectively), though similar to those used by Lotz et al. (2008). Hence, the errors for this study were large with the much smaller value of $n_{I}=0.0060 \mathrm{~min}^{-1}$ selected.

It should be noted that the data from the Sjostrand et al. study (2005a) was corrected prior to use in this analysis for the error present in the original article, as per their retraction (Sjostrand et al., 2005b)

\subsection{Comparison of results}

Using direct physiological measurements from 6 published microdialysis studies, the most appropriate parameter values $n_{I}=0.0060 \mathrm{~min}^{-1}, \gamma=0.5$ were identified. $\gamma=0.5\left(n_{I}=n_{C}\right)$ is unchanged from the values reported by Lin et al. (2011) and Lotz et al. (2008). However, $n_{I}=0.0060 \mathrm{~min}^{-1}$ is between the values reported in those two studies; $n_{I}=0.003 \mathrm{~min}^{-1}$ and $n_{I}$ $=0.0486 \mathrm{~min}^{-1}$.

The value of $n_{I}$ identified for the ICING model by Lin et al. (2011) was approximately 16-times smaller than that used by Lotz et al. (2008) for healthy and diabetic subjects. The result of this reduction in transcapillary diffusion $\left(n_{I}\right)$ and cellular insulin clearance rates, was that insulin persisted much longer in the interstitial compartment, reflecting the insulin pooling and delayed utilization effects observed in critically ill patients by Doran et al. (2005)

The parameter value for $n_{I}$ used by Lotz et al. (2008) was the transcapilliary diffusion rate for C-peptide identified by Van Cauter et al. (1992). This choice was justified on the grounds that insulin and C-peptide have similar molecular weights (5800 Da and 3600 Da respectively) and passive properties. Parameter values were identified for each individual based on age, gender, body surface area and diabetic or obese status, as proposed by Van Cauter et al. The mean value identified across the study cohort was $n_{I}=0.0486 \mathrm{~min}^{-1}$ (Lotz et al., 2008).

A possible reason for the discrepancy between the values identified in this study and those of Lotz et al. (2008) is that trans-endothelial insulin diffusion is a saturable process (Lin et al., 2011). The experimental diffusion rates adopted from Van Cauter et al. (1992) are determined by using C-peptide measurements. Although C-peptide has very similar molecular properties to insulin, it does not go through a high and variable degree of first pass extraction in the portal vein (Van Cauter et al., 1992). Therefore, its concentration is several folds higher than insulin in plasma. If the diffusion process is to any level saturable (Thorsteinsson, 1990), the rates determined using $\mathrm{C}$-peptide measurements would not be reflective of insulin.

The 'effective' or interstitial half-life of insulin is defined by the interstitial kinetic parameters in (3) (Lin et al., 2011). This half-life characterizes the clearance rate of insulin from the interstitium where it effects the uptake of glucose into tissue cells. Previously published reports suggest values in the range 25-130 mins (Mari and Valerio, 1997, Natali et al., 2000, Turnheim and Waldhausl, 1988).

$$
t_{1 / 2}=\frac{\log _{e}(2)}{n_{I}+n_{C}}
$$

The effective half-life associated with the kinetic parameters identified by Lin et al. (2011) was $t_{1 / 2}=116$ mins. This value better matched data from previous studies than the short $t_{1 / 2}=$ 7 mins used by Lotz et al. (2008). The effective half-life insulin determined from the values of $n_{I}$ and $n_{C}$ identified in this study is $t_{1 / 2}=58$ mins, is also within the range reported by previous studies.

\section{CONCLUSION}

This study used data from six published microdialysis studies to determine the most appropriate parameter values. Using direct physiological measurement data from the microdialysis studies provided a sound physiological foundation for the kinetic parameter values.

The results of this investigation suggest that the best values for the interstitial insulin kinetic parameters are $n_{I}=n_{C}=$ $0.0060 \mathrm{~min}^{-1}$. These parameter values are associated with an effective, interstitial insulin half-life $t_{1 / 2}=58$ mins, within the range of 25-130 mins reported by others.

\section{REFERENCES}

Castillo, C., Bogardus, C., Bergman, R., Thuillez, P. \& Lillioja, S. 1994. Interstitial insulin concentrations determine glucose uptake rates but not insulin resistance in lean and obese men. J Clin Invest, 93, 10-6.

Caumo, A. \& Luzi, L. 2004. First-phase insulin secretion: does it exist in real life? Considerations on shape and function. Am J Physiol Endocrinol Metab, 287, E371-85.

Doran, C., Chase, J., Shaw, G., Moorhead, K. \& Hudson, N. 2005. Derivative Weighted Active Insulin Control Algorithms and Intensive Care Unit Trials. Control Engineering Practice, 13, 1129-1138. 
Gudbjornsdottir, S., Sjostrand, M., Strindberg, L., Wahren, J. \& Lonnroth, P. 2003. Direct measurements of the permeability surface area for insulin and glucose in human skeletal muscle. J Clin Endocrinol Metab, 88, 4559-64.

Herkner, H., Klein, N., Joukhadar, C., Lackner, E., Langenberger, H., et al. 2003. Transcapillary insulin transfer in human skeletal muscle. Eur J Clin Invest, 33, 141-6.

Hovorka, R., Chassin, L. J., Ellmerer, M., Plank, J. \& Wilinska, M. E. 2008. A simulation model of glucose regulation in the critically ill. Physiol Meas, 29, 959-78.

Jansson, P. A., Fowelin, J. P., Von Schenck, H. P., Smith, U. P. \& Lonnroth, P. N. 1993. Measurement by microdialysis of the insulin concentration in subcutaneous interstitial fluid. Importance of the endothelial barrier for insulin. Diabetes, 42, 146973.

Jefferson, L. S. \& Cherrington, A. 2001. The endocrine pancreas and regulation of metabolism, Oxford, Oxford University Press.

Lin, J., Razak, N. N., Pretty, C. G., Le Compte, A., Docherty, P., et al. 2011. A physiological Intensive Control Insulin-Nutrition-Glucose (ICING) model validated in critically ill patients. Comput Methods Programs Biomed, 102, 192-205.

Lotz, T. F., Chase, J. G., Mcauley, K. A., Shaw, G. M., Wong, X. W., et al. 2008. Monte Carlo analysis of a new model-based method for insulin sensitivity testing. Comput Methods Programs Biomed, 89, 215-25.

Mari, A. \& Valerio, A. 1997. A Circulatory Model for the Estimation of Insulin Sensitivity. Control Eng Practice, 5, 1747-1752.

Natali, A., Gastaldelli, A., Camastra, S., Sironi, A. M., Toschi, E., et al. 2000. Dose-response characteristics of insulin action on glucose metabolism: a nonsteady-state approach. Am J Physiol Endocrinol Metab, 278, E794-801.

Pielmeier, U., Andreassen, S., Nielsen, B. S., Chase, J. G. \& Haure, P. 2010. A simulation model of insulin saturation and glucose balance for glycemic control in ICU patients. Comput Methods Programs Biomed, 97, 211-22.

Sjostrand, M., Gudbjornsdottir, S., Holmang, A., Lonn, L., Strindberg, L., et al. 2002. Delayed transcapillary transport of insulin to muscle interstitial fluid in obese subjects. Diabetes, 51, 2742-8.

Sjostrand, M., Gudbjornsdottir, S., Strindberg, L. \& Lonnroth, P. 2005a. Delayed transcapillary delivery of insulin to muscle interstitial fluid after oral glucose load in obese subjects. Diabetes, 54, 152-7.

Sjostrand, M., Gudbjornsdottir, S., Strindberg, L. \& Lonnroth, P. 2005b. Retraction - Delayed transcapillary delivery of insulin to muscle interstitial fluid after oral glucose load in obese subjects. Diabetes, 54, 2266.
Thorsteinsson, B. 1990. Kinetic models for insulin disappearance from plasma in man. Dan Med Bull, 37, 143-53.

Turnheim, K. \& Waldhausl, W. K. 1988. Essentials of insulin pharmacokinetics. Wien Klin Wochenschr, 100, 6572.

Van Cauter, E., Mestrez, F., Sturis, J. \& Polonsky, K. S. 1992. Estimation of insulin secretion rates from Cpeptide levels. Comparison of individual and standard kinetic parameters for C-peptide clearance. Diabetes, 41, 368-77.

Van Herpe, T., Pluymers, B., Espinoza, M., Van Den Berghe, G. \& De Moor, B. 2006. A minimal model for glycemia control in critically ill patients. Conf Proc IEEE Eng Med Biol Soc, 1, 5432-5. 